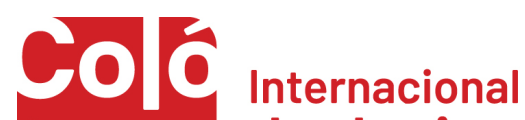 \\ of de design \\ EDIÇÃO 2020
}

\section{O papel do design no posicionamento da marca}

Priscilla Bettio Carvalho;

Taís de Souza Alves Coutinho

\section{resumo:}

O atual cenário competitivo das empresas e negócios tem sido influenciado pelo comportamento e hábitos da sociedade, exigindo assim a capacidade das organizações em planejar e implementar estratégias que ofereçam uma estrutura estável para os desafios encontrados no mercado. Quando uma marca está posicionada de maneira assertiva, todo o processo para alcançar os seus propósitos se tornam mais fáceis. Este artigo tem como objetivo apresentar como o design pode auxiliar no processo de posicionamento da marca. Realização de um estudo teórico que aborda os temas: marca, marketing, design como estratégia, branding e posicionamento. Através desse estudo, é possível propor contribuições de estratégias de design para um melhor posicionamento da marca no mercado.

\section{palaviras-chave:}

design como estratégia; branding; posicionamento 


\section{Introdução}

\subsection{Contextualização e Problematização}

Refletir sobre o papel do design dentro do universo das marcas é tratar sobre sua concepção, que resulta no impacto social que pode alcançar. Por isso, trabalhar os conceitos de design como estratégia de gestão pode ser imprescindível para a caracterização do diferencial de potencialização de uma marca. O design pode auxiliar com planos que viabilizem a produção de produtos e serviços. As empresas que almejam crescer no mercado, precisam investir em produtos e serviços que satisfaçam às necessidades e desejos dos consumidores. Assim, ao fazer a aplicação do design como estratégia de gestão da marca, as organizações agregam valor aos seus produtos e serviços, transmitindo aos consumidores os objetivos e a missão da empresa, mais especialmente atendendo às expectativas dos clientes (VATRAS, 2010, p.100).

$\mathrm{O}$ mercado demanda por produtos e serviços que atendam às pessoas além do que elas necessitam e desejam, e o design é o ponto chave para auxiliar o posicionamento de marcas com estratégias competitivas dentro de um contexto competidor, buscando assim inovação e oportunidades diferenciadas dentro dos negócios, sendo assim, um componente indispensável no cenário competitivo. Einsfeldt e Muller afirmam na Revista Moda Palavra que:

Atualmente o design não tem mais sido visto apenas como um resultado, mas sim como um processo dentro de uma organização, favorecendo a maior qualidade de gerenciamento e a transformação dos métodos tradicionais de gestão (EINSFELDT E MULLER, 2015, p.228).

A cultura, o meio social e os fenômenos emocionais são capazes de influenciar no hábito de consumo da sociedade. A mudança dos valores e dos conceitos da sociedade exigem um reposicionamento das marcas no mercado e requer delas novas formas de comunicação com o seu público.

Em razão disso, é muito importante que a comunicação do posicionamento de uma marca ou empresa seja realista, determinando um diálogo verdadeiro entre o cliente e a empresa. Este processo estratégico requer o conhecimento do ambiente do público que deseja atender, de forma que o posicionamento tenha conexão direta às estratégias do segmento da empresa (EINSFELDT E MULLER, 2015, p.232).

\section{Design como estratégia}

De acordo com Vatras (2010 p. 97 e 98), o design como estratégia de gestão empresarial é fundamental para compreender a importância da gestão do design, mostrando assim todo o diferencial em uma empresa pela maximização dos processos através dos planos estratégicos que dão sequência a todo um processo produtivo. A estratégia de gestão se torna um ponto chave para a conquista de muitas vantagens competitivas em relação tanto a qualidade de processos quanto a qualidade dos produtos e serviços. Dessa forma, fazer o uso do design como estratégia faz com que os empreendimentos tenham muito mais resultado.

Para Vatras (2010, p. 101), pensar como o designer dentro de uma empresa ou negócio pode ser a peça chave para alavancar os negócios e o que falta para entregar o valor dentro de cada produto e serviço aos seus clientes, entendendo cada vez mais o seu mundo, suas necessidades e desejos, para tornar o negócio mais compreensível e desejável. É importante trazer para o centro das discussões o conceito de design como gestão e mostrar como ele pode impactar diretamente as pessoas e empresas, como elas veem os resultados envolvidos em um certo contexto, resultando assim valor ao fazer uso dos benefícios dessa empresa.

Assim, as empresas e negócios podem identificar um caminho de competitividade, usando o design e os seus recursos como estratégia dentro de um novo posicionamento. 


\section{Marca}

Quando se pensa em uma marca, muitas vezes se leva em consideração a logo e o símbolo gráfico de uma empresa ou negócio, porém, a marca é muito mais que isso, é algo mais amplo. Martins (2006, p.8) traz como marca a definição: "podemos dizer que é a união de atributos tangíveis e intangíveis, simbolizados num logotipo, gerenciados de forma adequada e que criam influências e geram valor. Trata-se de um sistema integrado que promete entrega soluções desejadas pelas pessoas".

Para Cameira (2013, p.34 e 35), o conceito de marca tem uma diversidade sob vários pontos de vista, porém, os mais utilizados são os que focam em marketing evidenciando a diferenciação de bens e serviços. Porém, algumas organizações têm uma interpretação mais extensa e subjetiva, colocando assim a marca como um componente de grande valor definido e inalterável para empresas e consumidores.

Conforme Kotler e Keller (2012, p.258), uma marca é um bem ou serviço que acrescenta proporções que se diferenciam de outros produtos no mercado para satisfazerem a mesma necessidade. E essas diferenças podem ser funcionais, racionais, tangíveis, simbólicas, emocionais ou intangíveis, relacionadas a tudo que a marca representa ou significa.

A marca entrou no dicionário de todos. O termo é como um camaleão: o significado pode mudar de acordo com o contexto. [...] A marca tornou-se um sinônimo do nome de uma empresa e da sua reputação. As marcas estão gravadas em nossas vidas diárias, como em 'vamos xerocar isto' ou 'essa máquina não é uma Brastemp'. A obra de Andy Warhol e Heidi Cody lembra-nos dá força sempre presente das marcas como símbolos culturais mesmo aqueles que não sabem com clareza o que é uma marca desejam uma (WHEEKER, 2008, p.12).

De acordo com Kotler, autor de Administração de Marketing (2012), uma marca é o compromisso de uma empresa em proporcionar uma série de atributos particulares, benefícios e serviços semelhantes aos consumidores, sendo que as melhores marcam apresentam muita qualidade.

Em todas as definições acima, há um consenso de que as funções essenciais de uma marca são identificar e diferenciar. Algumas definições propõem uma abordagem mais ampla e subjetiva, que posiciona a marca como elemento pertencente a um sistema mais complexo de geração de valores tangíveis para as empresas e os consumidores (CAMEIRA, 2013, p.35).

Em busca de uma jornada de compras e experiencias, os consumidores estão rodeados por uma diversidade de opções, que precisam avaliar e analisar essas alternativas sendo produtos/serviços para então considerar o que aceitar ou rejeitar. O papel das marcas aparece como uma necessidade de conquistar a mente e coração dos consumidores a fim de induzi-los a essa decisão. Desta maneira, pode-se ver que a função de uma marca é muito importante, desde o início de sua construção onde deve ser forte e presente no mercado.

Para Braga (2016), a marca desempenha não só uma, mas várias funções, que podem variar de acordo com seu segmento de produto ou serviço. As principais funções são: identificar o produto ou serviço, esclarecer sua origem, garantir a qualidade e dar publicidade. A identificação de um produto ou serviço é muito relevante na hora da decisão de compra, pois a intenção é fazer com que consumidor tenha conhecimento e identifique o que está sendo oferecido através daquela marca. Quando a identidade de uma marca é forte seu consumidor nunca se confunde. O esclarecimento da origem de um produto ou serviço está relacionado à justificativa pela qual o cliente irá optar, qual a marca que ele irá escolher devido a diversas opções oferecidas no mercado. Outras questões importantes são a qualidade e a garantia. Sempre que o consumidor tem uma experiência positiva com uma marca sendo, a expectativa é que a qualidade do produto ou serviço que ele adquiriu seja constante. E dentro dessas funções da marca, o marketing tem a função de satisfazer os desejos e as 
necessidades dos clientes. Esta área estuda todo o comportamento do consumidor. Esse é um fator significativo de continuidade de um negócio/marca que atua no mercado, auxiliando assim as vendas e o crescimento da marca (KOTLER; KELLER, 2006, p. 172). Para ilustrar com mais clareza, o quadro abaixo apresenta as oito funções que uma marca pode transmitir ao consumidor:

1 Funções de uma marca - "Tabela"

\begin{tabular}{|c|c|}
\hline FUNÇÃO & BENEFÍCIO AO CONSUMIDOR \\
\hline De referência & $\begin{array}{l}\text { Ver claramente, situar-se em relação à produção sectorial, identificar } \\
\text { rapidamente os produtos procurados. }\end{array}$ \\
\hline De praticidade & $\begin{array}{l}\text { Permitir ganho de tempo e de energia na recompra de produto idêntico } \\
\text { pela fidelidade. }\end{array}$ \\
\hline De garantia & $\begin{array}{l}\text { Segurança de encontrar uma qualidade estável em todos os lugares e a } \\
\text { todo instante. }\end{array}$ \\
\hline De otimização & $\begin{array}{l}\text { Segurança de comprar o melhor produto de sua categoria, com o } \\
\text { melhor desempenho para um uso específico. }\end{array}$ \\
\hline De personalização & $\begin{array}{l}\text { Sentir-se reconfortado com sua autoimagem ou com a imagem que é } \\
\text { passada aos outros. }\end{array}$ \\
\hline De permanência & $\begin{array}{l}\text { Satisfação nascida da familiaridade e da intimidade das ligações com } \\
\text { uma marca que foi consumida durante anos e que ainda dura. }\end{array}$ \\
\hline Hedonista & Satisfação ligada à estética da marca, seu design e suas comunicações. \\
\hline Ética & $\begin{array}{l}\text { Satisfação ligada ao comportamento responsável da marca nas suas } \\
\text { relações com a sociedade (ecologia, emprego, cidadania, publicidade } \\
\text { não chocante). }\end{array}$ \\
\hline
\end{tabular}

Figura 1 - As oito funções que uma marca pode transmitir ao consumidor Fonte: Adaptação de Kapferer (2003, p.24)

Martins (1999, p.17) afirma que "o objetivo de toda empresa ao investir na construção de uma marca é aumentar sua lucratividade, fazendo que seus produtos deixem de ser commodities para se tornar referência no mercado". Os consumidores cada vez mais se identificam com as marcas e buscam produtos e serviços que lhes proporcionem prazer e bem-estar, procuram marcas que atendam às suas funções específicas, mas que tenham as suas próprias personalidades.

\section{Marketing}

Segundo Kotler e Keller (2012, p.3), marketing é um conjunto de atividades para a identificação de algo na tentativa de satisfazer as necessidades humanas e sociais, resultando em lucros. Uma outra definição escrita por eles: "eis uma definição social que atende aos nossos propósitos: marketing é um processo social pelo qual indivíduos e grupos obtêm o que necessitam e desejam por meio da criação, da oferta e da livre troca de produtos de valor entre si" (KOTLER E KELLER, 2012, p.4). Do ponto de vista de gestão, o marketing é visto como "a arte de vender produtos", mas muitos se enganam, pois de acordo com Kotler e Keller o primordial não é a venda.

O objetivo do marketing é conhecer muito bem o seu cliente, entender os seus hábitos, o seu 
comportamento e as suas ações. Dessa forma, fica muito mais simples um produto ou serviço moldarse ao cliente, conhecendo assim o seu mundo. Grandes são as necessidades e os desejos das pessoas em consumir e a maior motivação de compra é ter uma de suas necessidades não atendidas.

Uma empresa ou um negócio que deseja alcançar o sucesso precisa imergir afundo, buscando as informações do mundo do seu cliente para oferecer o melhor e sanar as suas necessidades. $\mathrm{O}$ marketing então estimula o desejo dentro das pessoas.

O marketing não deve mais ser considerado apenas sinônimo de vendas e/ou de uma ferramenta para gerar demanda. Deve, agora, ser considerado a principal esperança de uma empresa para recuperar a confiança do consumidor (KOTLER E KELLER, 2012, p.51).

\section{Branding}

De acordo com o administrador de empresas e consultor José Roberto Martins (2006, p.8), "branding é o conjunto de ações ligadas à administração das marcas". São ações que, tomadas com conhecimento e competência, levam as marcas além da sua natureza econômica, passando a fazer parte da cultura, e influenciar a vida das pessoas. Ações com a capacidade de simplificar e enriquecer nossas vidas num mundo cada vez mais confuso e complexo. "Ricardo Guimarães, consultor e diretor-presidente da Thymus Branding, definiu o Branding da seguinte forma:

$\mathrm{Na}$ Thymus, definimos marca como um nome ao qual as pessoas relacionam competências, atitudes e valores, que alimentam expectativas de entregas futuras que são materializadas por experiencias proporcionadas por uma cultura. Estas expectativas impactam a percepção de valor da marca e o custo de crescimento do negócio. Por isso gerenciar marca e gerenciar experiencias e expectativas, utilizando a percepção de valor como indicador de sucesso. Esta gestão de cultura da marca é que nós na Thymus, entendemos por branding (GUIMAR ̃̃ES, 2013).

[...] O branding é um programa estruturado que tem por objetivo garantir que os processos, a criação e o gerenciamento de marcas estejam integrados e, no final, gerem maior valor ao acionista. Em outras palavras, é um programa que busca alinhar a promessa e a entrega [...] (TOMIYA, 2010, p. 36).

Para Delano (2006), o Branding é um sistema de ações interdisciplinares, que propõe a criação de imagens, percepções e a conexão pela qual o consumidor tem com um produto ou serviço de uma empresa, apresentando o propósito de fazer com que a marca faça parte da cultura dos indivíduos e influencie o comportamento das pessoas, num processo de transmissão de valor para todas as partes interessadas da marca.

Uma outra definição de Branding por Valdenise Leziér Martyniuk,

Branding é a expressão que designa o conjunto das estratégias de marketing que visam ampliar o valor de uma marcal - seja a de um bem, serviço, linha de produtos ou empresa - em decorrência de sua visibilidade junto ao público, bem como de sua reputação e da associação a valores sociais positivos (MARTYNIUK, 2006, p.2).

Para Da Silva e Oliari (2017, p.6), o maior desafio de fazer Branding está na gestão das marcas, transformando design estratégico em valor, o cuidado na administração em que os gestores terão com essa marca, renovando a cada dia os seus valores, entendendo o que define a sua diferenciação no mercado, a fim de manter a sua identidade e originalidade, atendendo às necessidades 
e aos desejos dos seus clientes, pois essa é a chave para conquistar a confiança. Nessa nova era de competitividade, as empresas precisam se preocupar e colocar todo o seu olhar para a construção de marcas fortes e com presença no mercado, marcas que irão proporcionar experiências aos consumidores. Por isso, a tendência do branding é prosseguir com mudanças transformando-as assim em atividades estratégicas. Essa gestão fará com que as empresas ou os negócios tenham cada vez mais ferramentas estratégicas, gerando assim valor para a marca tendo assim resultando lucrativos.

Para Ono (2006, p.25) branding "é o conjunto de atividades que visa otimizar a gestão das marcas de uma organização como diferencial competitivo." O branding poder ser dividido em duas áreas: Estratégico e operacional. Dentro da área estratégica estão as ações de posicionamento e construção de uma marca. Já na área operacional compreendem os setores de pesquisa de mercado, comunicação, design, avaliação financeira e proteção legal. Dessa forma todas estas atividades conectadas podem ser entendidas como branding. A inserção do termo branding na cultura brasileira é bem assertiva, pois esta ferramenta oferece uma contribuição essencial para a construção de marcas fortes, uma grande necessidade das empresas (Ono, 2006, p.25).

De acordo com Silva (O Branding: ferramenta estratégica para o posicionamento de marca. p.1):

Pode-se entender que a marca vem sendo utilizada através dos tempos com o intuito de identificar e distinguir um produto ou serviços dos concorrentes. Entretanto, as marcas passaram a desempenhar papéis mais variados e complexos, e, com isso, houve a necessidade de adoção de um processo de gestão que favorecesse o reconhecimento e a fidelidade à marca por parte dos clientes.

Por isso é essencial entender que a marca não é apenas a logo ou a sua imagem, mas um conjunto de valores envolvidos que surge do resultado da relação da empresa com o mercado. Desta forma, a marca tem a competência de reunir ao seu redor todos os pontos tangíveis e intangíveis, de maneira que o seu valor seja assim reconhecido (SILVA. O Branding: ferramenta estratégica para o posicionamento de marca. p.2).

Analisando as definições citadas, é possível afirmar que o branding é um método de gerenciamento de marcas com o objetivo de gerar valor para elas, despertando o desejo, para assim transmiti-lo em forma de interesse para o seu público.

Assim pelo senso comum, pode-se concluir que o branding se define uma ferramenta de gestão concentrada nas marcas para que adquiram relevância no cotidiano de todos os públicos com os quais se relacionam. Mais do que um plano estratégico da marca, o branding está ligado as emoções despertadas por ela e aos vínculos que poderão ser estabelecidos com isso (CAMEIRA, 2013, p.47).

\section{0 posicionamento da marca}

O termo posicionamento de marca "tem diferentes significados para diferentes intérpretes. Existe consenso quanto a sua importância, mas bem pouco a respeito da sua definição e aplicação, especialmente do setor de serviços..." (MARTINS, 2006, p.57).

Para Keller e Machado (2006, p.70), o posicionamento implica na localização assertiva na mente de um grupo de consumidores ou um público alvo, de modo que eles pensem em um produto ou serviço com os seus próprios desejos e suas próprias necessidades. "Valor de mercado é igual a valorização. Encontrar um nicho pequeno de mercado para estruturar o posicionamento da marca é, muito importante e muito mais fácil de mensurar as necessidades e expectativas do cliente" (DA SILVA e OLARI, 2017, p.9).

Para Guimarães (2014), o posicionamento da marca é um resumo que declara com as suas qualidades e particularidades para os consumidores a sua diferenciação no mercado, considerando assim o contexto competitivo em que a marca se encontra, procurando distingui-la de seus concorrentes de forma atrativa.

Para Olari e da Silva (2017, p.10), analisando todo o método de gestão de posicionamento de 
valor de uma marca, deve-se voltar uma atenção especial em alguns elementos como, a cultura e os valores de seus proprietário, transmitindo assim mais valor para a marca, fazendo com que ela se destaque e seja distinguida com os seus diferenciais entre muitas no mercado, com isso será percebida de forma diferente pelos consumidores.

Todas as marcas evoluem em camadas de tempo e lugar, não sendo de se esperar que uns poucos estímulos, descoordenados e de curta duração, produzam uma mudança radical na sua concepção e na percepção dos consumidores. Em dado momento, verificamos que a estratégia de marca, finalmente é a marca (MARTINS, 2006, p.58).

Para Tomiya (2010, p.63), dentro do posicionamento de uma marca é preciso conter os seguintes atributos que mostra o quadro abaixo:

2 Atributos de uma marca - "Tabela"

\begin{tabular}{|c|c|c|c|}
\hline CONFIÁVEL & RELEVANTE & ÚNICO & PERENE \\
\hline $\begin{array}{c}\text { Pessoas acreditam } \\
\text { que a marca pode } \\
\text { entregar }\end{array}$ & $\begin{array}{c}\text { Faz a diferença para } \\
\text { as pessoas }\end{array}$ & $\begin{array}{c}\text { Somente sua marca } \\
\text { pode prometer }\end{array}$ & $\begin{array}{c}\text { Resiste às mudanças } \\
\text { de cenário }\end{array}$ \\
\hline
\end{tabular}

Figura 2 - Tabela dos brand scorecards: sistema de métrica para monitoramento Fonte: Autor adaptação de Tomiya (2010, p.63)

Trabalhar com o valor da marca, e com tudo que ela representa através de sua história é a melhor oportunidade de crescer.

Analisando o contexto das grandes marcas, podemos perceber que as mesmas vêm munidas de grandes histórias. Seus posicionamentos são muito concisos e fortes. É o caso da Apple, que simplesmente não vende produtos, vende sonhos. Steve Jobs era um grande articulador no processo de branding da Apple. Por causa da sua ironia concisa ele gerou muitas revoluções ao longo de sua jornada. Todas elas marcadas positivamente de alguma maneira. A empresa passou por alguns momentos delicados, porém, o fato de comportamento estratégico da marca em vender valor e nunca um produto fez da Apple, uma das mais valiosas marcas do mundo. É um outro exemplo de que posicionamento de marca não se cria, mas se define. (OLARI E DA SILVA, 2017, p.11).

Para Einsfeldt e Muller (2015, p.245), o design é um processo qualificado para oferecer vários benefícios às empresas que o englobam. Com isso, o posicionamento através dele acaba sendo automático dentro das empresas, pois ele agrega valor aos produtos e serviços, resultando na compreensão dos consumidores e na identificação das tendências que criam futuras ações, tornando possível o desenvolvimento de produtos qualificados para atender às necessidades específicas e subjetivas de cada cliente, propiciando novidades nas experiências oferecidas.

"Existem seis formas de se posicionar, mas você tem que honrar a promessa ao escolher: melhor preço, melhor produto ou serviço, serviços de valor agregado, facilidade de acesso/conveniência, experiência do cliente/experiências memoráveis" (GUIMARÃES, 2014, p.27).

Para Guimarães (2014, p.27), o posicionamento de uma marca considera todo o contexto em que a marca está inserida, buscando assim distingui-la das demais. Dentro do posicionamento da marca, o branding não leva em consideração somente o atual cenário que ela está inserida, mas também sua essência e suas particularidades almejadas. 
É necessário citar sobre o tema diferenciação, pois ele faz parte de todo o processo de posicionamento de uma marca. De acordo com SEBRAE (Serviços Brasileiro de Apoio às Micro e Pequenas Empresas), a diferenciação é a capacidade que uma empresa tem de ser percebida como diferente dos concorrentes, em função de suas vantagens competitivas. Ela pode se diferenciar a partir da segmentação de seu mercado, seu posicionamento e seu mix de marketing (produto, preço, promoção e ponto-de-venda/distribuição).

Ainda de acordo com uma cartilha do SEBRAE (Serviços Brasileiro de Apoio às Micro e Pequenas Empresas) - Posicionamento e comunicação - A receita do sucesso, nem toda diferença é considerada significativa. Ela deve ser estabelecida até satisfazer os seguintes critérios:

- Importância: oferece um benefício de alto valor;

- Destaque: é oferecida de maneira destacada;

- Superioridade: é superior a outras maneiras de se obter o benefício;

- Exclusividade: não pode ser facilmente copiada pela concorrência;

- Acessibilidade: o comprador deve poder pagar pela diferença;

- Lucratividade: deve ser lucrativa para a empresa.

Para OLARI e DA SILVA (2017, p. 12), o posicionamento que a empresa conquista é gerado baseando se primeiramente nos consumidores. Dessa forma, diz que o posicionamento não se cria se define, possuindo a estrutura principal sendo ela a cultura e os valores de seus proprietários, ou seja, tudo o que envolve a identidade e o jeito da marca de ser. Segundo SEBRAE (Serviços Brasileiro de Apoio às Micro e Pequenas Empresas), a receita do sucesso: as estratégias de posicionamento devem ser fundamentadas em estudos da mente do consumidor. Veja três importantes estratégias:

- Fortalecer a posição do produto na mente dos consumidores;

- Buscar uma posição não ocupada que seja valorizada por muitos consumidores e ocupá-la;

- Descolar da posição do concorrente.

De acordo com OLARI e DA SILVA, para trabalhar com a oportunidades posicionamento é preciso definir quais são estas oportunidades.

3 Principais pontos para o posicionamento de uma marca - "Tabela"

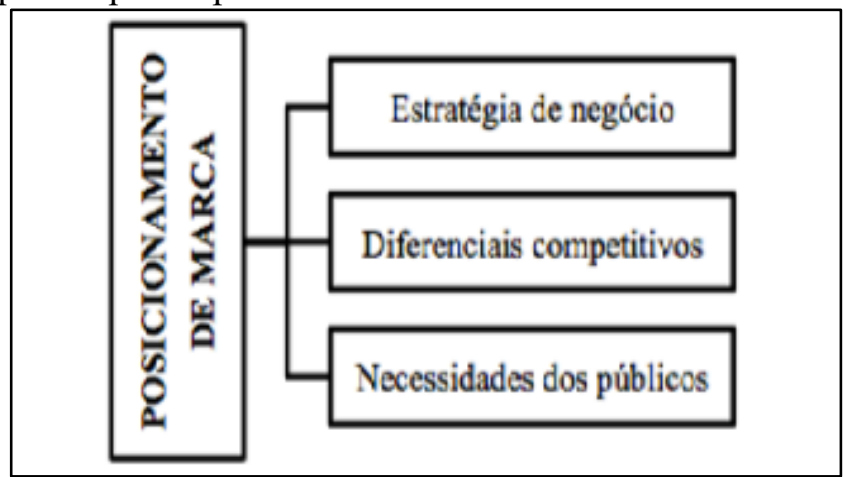

Figura 3 - Tabela das três dimensões para análise de oportunidades Fonte: autor adaptação de Tavares

(2008, p. 181) Fonte: autor adaptação de Tavares (2008, p. 181)

"O posicionamento é uma forma de se diferenciar no mercado e agregar valor aos produtos oferecidos" (SEBRAE-Serviços Brasileiro de Apoio às Micro e Pequenas Empresas). Esta estrutura de posicionamento tem como objetivo definir quais os passos que a empresa irá tomar em relação a sua identidade para se posicionar a frente dos concorrentes no mercado dos negócios. Esta estrutura é a chave para conseguir um ótimo posicionamento de uma marca.

Conforme OLARI E DA SILVA (2017, p.14), a identidade da marca é a sua fiel identificação 
da sua personalidade, pois é ela que irá determinar um posicionamento aos consumidores dentro do seu ambiente competitivo.

Para Einsfeldt e Muller (2015, p.246) o posicionamento através do design pode beneficiar a imagem das marcas no mercado, proporcionando o alinhamento da comunicação, desenvolvendo assim identidades fortes e coerentes.

Com isso o design como estratégia para o posicionamento de uma marca deve ser utilizado nas empresas, pois sua aplicação traz mudanças significativas. Em primeira mão, é preciso entender os dois mundos: cliente e mercado. Após essa imersão, é necessário traçar as estratégias de elaboração do plano de ação da empresa. Para traçar o plano de ação e poder ter um grande diferencial dentro da empresa, o design de serviço se torna um aliado essencial, mostrando assim a sua relevância estratégica para o sucesso de uma marca.

"Desse espectro, empresas que são provedoras de serviços têm em mãos a possibilidade de criar algo único e relevante para seus clientes. Têm em mãos a possibilidade de atender uma dor e criar comportamentos." (TIROLI, Paulo. 3 tendências de Design de serviço, 2017).

A partir disso, é feito o posicionamento utilizando as ferramentas de design, utilizando-as em cada etapa, a fim de identificar as mudanças e apresentar uma resposta rápida.

\section{Design como estratégia de gestão}

De acordo com o livro: Design estratégico aplicado, uma experiência colaborativa entre universidade e empresa da UNISINOS - UNIVERSIDADE DO VALE DO RIO DOS SINOS - Franzato e Reyes (2014, p.8), o design estratégico projeta estratégias organizacionais, inserindo todo o planejamento de estratégias com ideias e planos alternativos, acompanhando assim todos os planos da empresa. Para Franzato (2014, p.8), o design é um processo criativo que muda cenários e contextos. Uma situação problemática é explorada e interpretada com bastante agilidade e rapidez e então é elaborada estratégias mais eficientes para o desenvolvimento de projetos e a sua implementação.

Diferentemente do planejamento estratégico, o design estratégico não planeja, mas justamente projeta as estratégias organizacionais. Pulando passagens lógicas, as joga em direção a visões originais de futuro, desejáveis antes do que plausíveis. Dessa forma, o design estratégico complementa o planejamento estratégico com propostas alternativas que possam inspirar, se não mesmo guiar, a elaboração das estratégias (FRANZATO, 2014, p.9).

Para Vatras (2010, p. 99), o design como estratégia de gestão procura posicionar com excelência uma empresa, assim como sua marca e dentro dela seus produtos e serviços de consumo, dentro do mercado alvo, ou seja dentro do contexto em que estão inseridos, através das estratégias competitivas obtida com os processos estratégicos. O design como estratégia de gestão aborda como será administrado todas as atividades de design dentro de uma empresa, encaminhando assim aperfeiçoamentos e melhorias em curto, médio e longo prazo, através do desenvolvimento de produtos e serviços conforme o desejo e necessidades dos consumidores, sendo assim uma estratégia que facilita as empresas a aumentar a sua eficiência, continuar competitiva e se diferenciar no mercado.

\section{Considerações Finais}

As ações de design estabelecidas consistem em uma proposta inicial para algumas sugestões para a empresa, mostrando assim que o design contribui para o crescimento e o avanço permanente de uma organização. Para Martins (2004, p.156) O grande avanço da concorrência é influenciado pelas novas tecnologias e novas formas dos mercados competitivos, incorporando cada vez mais a sociedade. Consequentemente os empresários sentem na pele e começam a entender que o design é a peça chave de uma empresa, e precisa ser visto como um recurso essencial e indispensável. "A estratégia de design define como a organização pretende utilizar o design, e como o processo de design pode melhor servir às suas necessidades operacionais" (BEST, 2003, p.49). 
O Design busca alternativas viáveis, aperfeiçoando o processo de comunicação entre a empresa e o consumidor, aproximando o produto do seu público. Para Martins (2004 p.156) a gestão de Design busca o equilíbrio certo para as ações implementadas na empresa, pois o design através da sua evolução histórica tem tomado uma posição de valor no âmbito empresarial, experienciando todos os problemas enfrentados, estudando a fundo sobre mercados, projetos, público, marca e estratégias. Sendo assim o design assume um posicionamento de estratégias e criação de soluções de projeto integrado, seja na parte de produto ou na comunicação, deixando assim o conceito de autor de projetos isolados de lado.

O objetivo de propor as contribuições de design para uma empresa demonstra a importância de identificar como as metodologias e o design como estratégia podem auxiliar no posicionamento de uma marca, determinando assim o valor que o design tem, atuando como uma ferramenta criativa de grande relevância nas empresas e nos negócios.

The role of design in brand positioning

\section{Abstract}

The current competitive scenario of companies and businesses has been influenced by the behavior and habits of society, thus requiring the ability of organizations to plan and implement strategies that offer a stable structure for the challenges encountered in the market. When a brand is positioned in an assertive way, the whole process to achieve its purposes becomes easier. This article aims to present how design can assist in the brand positioning process. Conducting a theoretical study that addresses the topics: brand, marketing, design as strategy, branding and positioning. Through this study, it is possible to design proportions of strategies for a better positioning of the brand in the market.

Keywords: design as a strategy; branding; positioning

\section{Referências}

BRAGA, Cristiano. Pretes. Qual é a função da marca: Qual é a função da marca. 2016. Disponível em: http://www.cpb.adv.br/qual-e-a-funcao-da-marca/. Acesso em: 24/04/19.

CAMEIRA, Sandra. Ribeiro. Branding + Design: 0 branding e a metodologia de sistemas de identidade visual. São Paulo. 2013.

EINSFELDT, Cristine; MULLER, Vera. Denise. A percepção do Design como posicionamento no segmento de moda. Moda palavra e-periódico. Vol 8, n.15 p.222-248, janeiro/julho. 2015.

FRANZATO, Carlo; Reyes, Paulo. Design Estratégico Aplicado: Uma experiencia colaborativa entre universidade e empresa. Porto Alegre. 2014.

GUIMARÃES, Ricardo. Branding: Qual a alma da sua empresa. Endeavor Brasil. 2015

KELLER, Lane. Kevin; MACHADO, Marcos. Gestão estratégica de marcas. São Paulo: Pearson Education do Brasil. 2006.

KOTLER, Philip; KELLER, Kevin, L. Administração De Marketing. Edição 14. São Paulo: Pearson, 2012. 
KOTLER, Philip; et al. Marketing 3.0: As forças que estão definindo o novo marketing centrado no ser humano. Rio de Janeiro: Elsevier. 2012.

LENCASTRE, Paulo, de. 0 livro da Marca. Lisboa: Dom Quixote. 2005.

MARTINS, José. Roberto. Branding: Um manual para você criar, gerenciar e avaliar marcas. $3^{a}$ Edição. São Paulo: Global Brands. 2006.

MARTYNIUK, Valdenise. Leziér. Olhares sobre o Branding. Academos revista eletrônica da FIA. Vol II, n.2, p.46-56, julho-dezembro. 2006.

ONO, Fabíola. Gestão da marca (branding) SENAC PARANÁ, Curitiba 2006.

SEBRAE. Posicionamento e comunicação: a receita do sucesso. Brasília, IBRAVIN, 2012.

SILVA, Giorgio. O BRANDING: Ferramenta estratégica para o posicionamento da marca. Universidade do Vale do Itajaí.

TIROLI. Paulo. 3 tendências do design de serviços - 2017 -

https://escoladesignthinking.echos.cc/blog/2017/04/3-tendencias-de-design-de-servicos/- Acesso em 01/11/19.

VATRAS, Amanda. Design como estratégia de gestão. dObra[s]: revista da Associação Brasileira de Estudos de Pesquisas em Moda. Vol.4, número 8, páginas 96-102, 2010. 